\title{
ADEQUAÇÃO DE MÉTODOS INDIRETOS PARA ESTIMATIVA DA ERODIBILIDADE DE SOLOS COM HORIZONTE B TEXTURAL NO BRASIL(1)
}

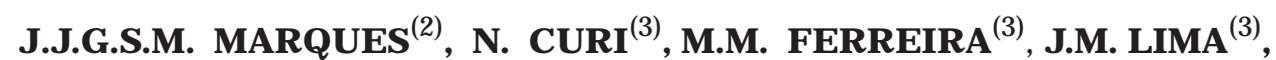 \\ M.L.N. SILVA ${ }^{(4)} \&$ M.A. CAROLINO de SÁ(2)
}

\begin{abstract}
RESUMO
O conhecimento da erodibilidade dos solos (fator $K$ ) é de fundamental importância para a aplicação da equação universal de perdas de solo (EUPS). 0 objetivo deste trabalho foi verificar a adequação de diferentes métodos indiretos para estimativa da erodibilidade de solos com horizonte B textural (Bt) de várias regiões geográficas do Brasil. Coletaram-se amostras superficiais de 22 solos com $B t$, cujo fator $K$ foi determinado diretamente no campo. Realizaram-se diversas análises químicas e físicas, de modo que o fator $\mathrm{K}$ pudesse ser estimado por treze diferentes métodos indiretos. Correlacionaram-se os valores dos fatores $\mathrm{K}$ medidos no campo com os obtidos indiretamente. Verificou-se que nenhum dos métodos indiretos testados é adequado para a estimativa do fator $\mathrm{K}$ de todo o conjunto de solos com Bt estudados.
\end{abstract}

Termos de indexação: erosão, fator K, equação universal de perdas de solo.

\section{SUMMARY: ADEQUACY OF INDIRECT METHODS TO ESTIMATE THE ERODIBILITY OF SOILS WITH ARGILLIC HORIZON IN BRAZIL}

Theassessment of thesoil erodibility ( $\mathrm{K}$-factor) is essential for using the universal soil loss equation. Theobjective of this paper was to verify the adequacy of different indirect methods to estimate the K-factors of soils with argillic horizon from diversegeographic regions of Brazil. Superficial samples of 22 soils bearing argillic horizon were coll lected. The K-factors measured directly in thefiel d of all these soi Is areal ready known. Several chemical and physical analyses were performed in order to calculate the K-factor by 13 indirect methods. The calculated Kfactors were correlated with the direct $\mathrm{K}$-factor value It was verified that none of the indirect methods tested is suitablefor estimating theK-factor of all studied soi ls with argillichorizon in Brazil.

Index terms: erosion, K-factor, USLE.

\footnotetext{
(1) Parte da Dissertação de Mestrado apresentada pelo primeiro autor à Universidade Federal de Lavras (MG). Recebido para publicação em julho de 1996 e aprovado em maio de 1997.

(2) Aluno de Mestrado do CPGSNP - Universidade Federal de Lavras, Caixa Postal 37, CEP 37200-000 Lavras (MG).

(3) Professor, UFLA - Departamento de Ciência do Solo, Caixa Postal 37, CEP 37200-000 Lavras (MG). Bolsista do CNPq.

(4) Pesquisador, EMBRAPA-Centro Nacional de Pesquisa de Solos, Rua J ardim Botânico, 1024, CE P 22460-000 Rio de J aneiro (RJ ).
} 


\section{INTRODUÇÃO}

A equação universal de perdas de solo (USLE) (Wischmeier \& Smith, 1978) éamplamente utilizada, principalmente nos EUA (Renard et al., 1994). Além dessa, existe uma série de modelos baseados em processos físicos, entre os quais a WEPP, que são opostos ao empirismo da USLE. No entanto, esses parecem não ser tão eficientes e práticos quanto a USLE, devido ao grande número de informações necessárias para o bom funcionamento do modelo (Renard et al., 1994).

A erodibilidade do solo, que representa o efeito integrado dos processos que regulam a infiltração de água e a resistência do solo à desagregação e transporte de partículas ( $\mathrm{Lal}, 1988$ ), é ofator que tem despertado maior interesse na pesquisa de erosão do solo propriamente dita, por ser, obviamente, relacionado ao solo e, portanto, variar significativamente de solo para solo. Para que fosse possível utilizar a erodibilidade do solo como um fator da USLE, foi preciso impor-lhe algumas restrições (Bryan et al., 1989). Assim, a erodibilidade do solo (fator K) foi redefinida como a quantidade de solo perdido em dada área por unidade do índice de erosividade adotado, nas condições padrão (Wischmeier \& Smith, 1978). O fator K medido no campo (método direto), por meio de chuvas simuladas ou naturais, é considerado o val or que verdadeiramente reflete a erodi bilidade do solo, tal como ela é compreendida na USLE. No entanto, o método direto, além de necessitar de determinações morosas e de alto custo, principalmente quando medido mediante chuvas naturais, requer também rigorosa padronização.

As equações que permitem estimar o fator $K$ são desenvolvidas, geralmente, por meio de regressões múltiplas entre o fator $\mathrm{K}$ medido diretamente no campo e os atributos do sol o, quando apresentam boa correlação, podendo, assim, fornecer o fator de erodibilidade do solo (fator K) para uso na USLE. Essas equações, porém, não refletem, obrigatoriamente, relações de causa e efeito, mas podem ser empregadas, desde que forneçam valores próximos aos medidos diretamente (Römkens, 1987).

O mais conhecido método indireto para estimativa do fator $\mathrm{K}$ é o nomograma proposto por Wischmeier et al. (1971). Na sua elaboração, foram incluídos, dominantemente, solos de textura média do MeioOeste dos EUA. Talvez por isso, tem sido freqüentemente observada sua inadequação às condições brasileiras (Henklain \& Freire, 1983; Silva et al ., 1986; Denardin, 1990; Lima, 1991; Silva, 1994; Silva et al., 1994). Respostas positivas à utilização desse modelo são menos freqüentes (Silva et al., 1986; Campos Filho et al., 1992). Tendo em vista a inaplicabilidade do método de Wischmeier et al. (1971) ao Brasil, outros métodos indiretos ou adaptações do mesmo têm sido testados (Lima et al., 1990; Denardin, 1990; Silva, 1994; Silva et al., 1994), os quais ainda necessitam de revalidação dos resultados. Mesmo métodos desenvol vidos e/ou adaptados às condições brasileiras
(Denardin, 1990; Lima et al., 1990) não podem ser empregados sem restrições (Silva et al., 1994).

Com base no exposto, este trabal ho teve por objetivo comparar diferentes métodos indiretos de avaliação da erodibilidade com o valor do fator $\mathrm{K}$ medido diretamente no campo, para solos com horizonte $B$ textural de diferentes regiões do Brasil.

\section{MATE RIAL E MÉTODOS}

Coletaram-se amostras do horizonte $A$ de 22 solos cujo fator $\mathrm{K}$ foi determinado diretamente no campo. $O$ val or do fator $K$, medido di retamente, a classificação e a localização dos solos estudados encontram-se no quadro 1. Alguma discordância entre a classificação dos sol os desse quadro 1 ea apresentada nos trabal hos em que o fator $K$ foi originalmente publicado se deve a mudanças nos critérios de classificação. Neste trabal ho, usou-sea proposta por Camargo et al. (1987), baseando-se na descrição morfológica eem resultados analíticos. Os valores do fator K determinados sob chuvas simuladas diferem dos originais devido à correção proposta por Denardin (1990). A figura 1 mostra a distribuição dos sol os estudados no Brasil.

Na fração TFSA, realizou-se a análise granulométrica pelo método da pipeta (Day, 1965), empregando-se a dispersão da amostra em suspensão com água, com e sem $\mathrm{NaOH} 1 \mathrm{~mol} \mathrm{L-1}$.

A proporção de agregados menores que $0,25 \mathrm{~mm}$, também chamada deíndice deinstabilidade(EI-Swaify \& Dangler, 1977), foi determinada através de peneiramento úmido, sem pré-umedecimento e descontando-se a contribuição da fração areia

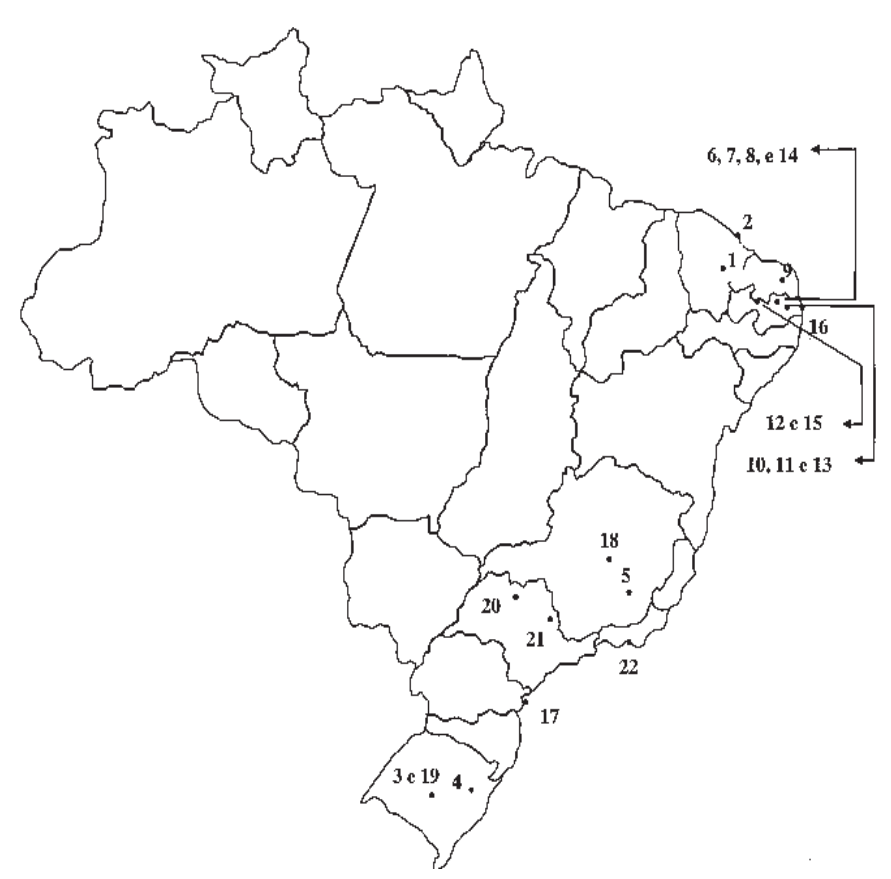

Figura 1. Distribuição dos solos estudados no território brasileiro. 


\section{Quadro 1. Classificação, localização, fator K (K obs.) e fonte do fator K dos solos estudados}

\begin{tabular}{|c|c|c|c|c|}
\hline No & Classificação & Localização & K obs. & Fonte \\
\hline & & \multicolumn{3}{|c|}{$\mathrm{th}(\mathrm{MJ} \mathrm{mm})^{-1}$} \\
\hline 1 & $\begin{array}{l}\text { Podzólico vermel ho-amarelo eutrófico Tb plíntico A fraco } \\
\text { textura arenosa/argilosa fase caatinga hiperxerófila rel evo } \\
\text { plano }\end{array}$ & Quixadá (CE) & 0,008 & 1 \\
\hline 2 & $\begin{array}{l}\text { Podzólico amarelo eutrófico Tb A moderado textura } \\
\text { arenosa/média fase caatinga hipoxerófila relevo plano }\end{array}$ & Fortaleza (CE) & 0,045 & 1 \\
\hline 3 & $\begin{array}{l}\text { Podzólico vermel ho-escuro distrófico Ta A moderado textura } \\
\text { média/argilosa fase campo relevo ondulado }\end{array}$ & Santa Maria (RS) & 0,024 & 2 \\
\hline 4 & $\begin{array}{l}\text { Podzólico vermel ho-escuro distrófico Tb A moderado textura } \\
\text { média/argil osa fase campo rel evo ondulado }\end{array}$ & Eldorado do Sul (RS) & 0,034 & 3 \\
\hline 5 & $\begin{array}{l}\text { Podzólico vermel ho-amarelo distrófico Tb câmbico A } \\
\text { moderado textura argilosa/muito argilosa fase floresta } \\
\text { tropical subperenifólia relevo suave ondulado }\end{array}$ & Viçosa (MG) & 0,027 & 4 \\
\hline 6 & $\begin{array}{l}\text { Podzólico vermel ho-amarelo eutrófico Tb A moderado textura } \\
\text { média fase floresta tropical subperenifólia/subcaducifólia } \\
\text { relevo suave ondulado }\end{array}$ & Alagoa Grande (PB) & 0,032 & 5 \\
\hline 7 & $\begin{array}{l}\text { Podzólico vermel ho-escuro eutrófico Tb plíntico A } \\
\text { proeminente textura média/argil osa fase floresta tropical } \\
\text { subcaducifólia relevo suave ondulado }\end{array}$ & Itapororoca (PB) & 0,018 & 5 \\
\hline 8 & $\begin{array}{l}\text { Bruno não cálcico A moderado planossólico textura média } \\
\text { fase floresta tropical caducifólia relevo suave ondulado }\end{array}$ & Gurinhém (PB) & 0,032 & 5 \\
\hline 9 & $\begin{array}{l}\text { Solonetz-solodizado Ta A moderado textura arenosa/argilosa } \\
\text { fase caatinga hiperxerófila rel evo suave ondulado }\end{array}$ & Boa Vista (PB) & 0,012 & 6 \\
\hline 10 & $\begin{array}{l}\text { Bruno não cálcico A fraco textura média fase caatinga } \\
\text { hiperxerófila relevo suave ondulado }\end{array}$ & Patos (PB) & 0,008 & 7 \\
\hline 11 & $\begin{array}{l}\text { Podzólico vermelho-escuro eutrófico Tb A fraco textura } \\
\text { média fase caatinga hiperxerófila rel evo suave ondulado }\end{array}$ & Patos (PB) & 0,004 & 6 \\
\hline 12 & $\begin{array}{l}\text { Podzólico vermel ho-amarel o eutrófico Tb A fraco textura } \\
\text { média/argil osa fase caatinga hipoxerófila rel evo suave } \\
\text { ondulado }\end{array}$ & Tavares (PB) & 0,025 & 7 \\
\hline 13 & $\begin{array}{l}\text { Podzólico vermel ho-escuro eutrófico Tb A moderado textura } \\
\text { média/argilosa fase caatinga hipoxerófila relevo suave } \\
\text { ondulado }\end{array}$ & Teixeira (PB) & 0,008 & 7 \\
\hline 14 & $\begin{array}{l}\text { Podzólico vermel ho-amarelo álico Ta A proeminente textura } \\
\text { média fase floresta tropical subperenifólia/subcaducifólia } \\
\text { relevo suave ondulado }\end{array}$ & Alagoa Nova (PB) & 0,031 & 5 \\
\hline 15 & $\begin{array}{l}\text { Bruno não cálcico A fraco textura média/argilosa fase } \\
\text { caatinga hipoxerófila relevo suave ondulado }\end{array}$ & Casserengue (PB) & 0,009 & 6 \\
\hline 16 & $\begin{array}{l}\text { Podzólico vermel ho-amarel o eutrófico Tb A proeminente } \\
\text { textura média fase floresta tropical subcaducifólia rel evo } \\
\text { ondulado }\end{array}$ & Glória do Goitá (PE) & 0,014 & 8 \\
\hline 17 & $\begin{array}{l}\text { Podzólico vermel ho-amarelo álico Ta A moderado textura } \\
\text { argilosa/muito argilosa fase floresta tropical perenifólia } \\
\text { relevo forte ondulado }\end{array}$ & Morretes (PR) & 0,004 & 9 \\
\hline 18 & $\begin{array}{l}\text { Podzólico vermel ho-amarelo eutrófico Tb A moderado textura } \\
\text { argilosa/muito argilosa fase floresta tropical subperenifólia } \\
\text { relevo ondulado }\end{array}$ & Sete Lagoas (MG) & 0,033 & 10 \\
\hline 19 & $\begin{array}{l}\text { Podzólico vermel ho-escuro álico Ta A moderado textura } \\
\text { média/argilosa fase campo relevo ondulado }\end{array}$ & Santa Maria (RS) & 0,032 & 3 \\
\hline 20 & $\begin{array}{l}\text { Podzólico vermel ho-escuro eutrófico Ta A moderado textura } \\
\text { arenosa/média fase floresta latifoliada tropical rel evo suave } \\
\text { ondulado a ondulado }\end{array}$ & Pindorama (SP) & 0,004 & 11 \\
\hline 21 & $\begin{array}{l}\text { Podzólico vermel ho-amarelo eutrófico Tb A chernozêmico } \\
\text { textura argil osa fase floresta tropical subcaducifólia relevo } \\
\text { ondulado }\end{array}$ & Mococa (SP) & 0,023 & 12 \\
\hline 22 & $\begin{array}{l}\text { Podzólico vermel ho-escuro eutrófico Tb A moderado textura } \\
\text { média/argilosa fase floresta tropical subcaducifólia relevo } \\
\text { suave ondulado }\end{array}$ & I taguaí (RJ ) & 0,028 & 13 \\
\hline
\end{tabular}

\footnotetext{
${ }^{(1)}$ Silva (1994). ${ }^{(2)}$ Dal Conte (1982). ${ }^{(3)}$ Levien, citado por Denardin (1990). ${ }^{(4)}$ Resck et al. (1981). ${ }^{(5)}$ Rodrigues do Ó (1986). ${ }^{(6)}$ Silva \& Andrade (1994). ${ }^{(7)}$ Silva et al. (1986). ${ }^{(8)}$ Campos Filho et al. (1992). ${ }^{(9)}$ EMBRAPA-CNPF (informação pessoal do pesquisador G.R. Curcio). ${ }^{(10)}$ Marques (1996). ${ }^{(11)}$ Carvalho et al. (1994). ${ }^{(12)}$ Carvalho et al. (1989). ${ }^{(13)}$ Leprun, citado por Denardin (1990).
} 
(usando-se $\mathrm{NaOH} 1 \mathrm{~mol} \mathrm{~L}^{-1}$ ) de tamanho superior ao da peneira em que os agregados ficaram retidos $(0,25 \mathrm{~mm})$, conforme Kemper \& Rosenau (1986). As classes de estrutura e permeabilidade foram codificadas de acordo com Wischmeier et al. (1971), com base na descrição geral do perfil dos solos e na descrição morfológica do horizonte A. Assim, a estrutura foi codificada em: (a) muito pequena granular $=1$; (b) pequena granular =2; (c) média a grande granular = 3; e (d) blocos, laminar ou maciça $=4$. A permeabilidade foi codificada em: (1) rápida $=1$; (2) moderada a rápida $=2$; (3) moderada $=3$; (4) lenta a moderada $=4 ; \mathrm{e}(5)$ lenta $=5$.

As análises do complexo sortivo, pH (em água e em KCl 1 mol L-1), matéria orgânica, $\mathrm{Fe}_{2} \mathrm{O}_{3}$ e $\mathrm{Al}_{2} \mathrm{O}_{3}$, extraídos pelo ataque sulfúrico, foram feitas segundo Vettori (1969) e Embrapa (1979), determinando-se $\mathrm{Fe}_{2} \mathrm{O}_{3}, \mathrm{Al}_{2} \mathrm{O}_{3}$ e $\mathrm{SiO}_{2}$, extraídos pelo ditionito-citratobicarbonato de sódio (DCB) da fração argila, segundo Mehra \& J ackson (1960). A determinação do $\mathrm{Fe}_{2} \mathrm{O}_{3}$ DCB foi feita por meio deabsorção atômica e do $\mathrm{Al}_{2} \mathrm{O}_{3}$ - DCB, pelo método do aluminon (M cK eague, 1978), sendo a destruição do citrato obtida por meio da combinação dos métodos de McK eague (1978) e Camargo et al. (1986). O teor de $\mathrm{SiO}_{2}-\mathrm{DCB}$ foi obtido segundo Weaver et al. (1968). Todas as anál ises químicas e físicas foram efetuadas com quatro repetições.

Foram testados treze métodos indiretos de avaliação do fator $K$ da USLE. As equações tiveram seus coeficientes corrigidos para que recebessem os val ores das variáveis e fornecessem o do fator $\mathrm{K}$ em unidades S.I . Portanto, em todas as equações, o fator $\mathrm{K}$ tem como unidade $\mathrm{h}(\mathrm{MJ} \mathrm{mm})^{-1}$ e as variáveis, $\mathrm{o}$ mesmo significado. As equações utilizadas foram as seguintes:

1) Wischmeier et al. (1971)

Método desenvol vido para solos de textura média do Meio-Oeste dos EUA:

$$
\begin{aligned}
K= & 1,451 \times 10-10(120-M O) M^{1,14}+ \\
& +0,0043(\mathrm{~S}-2)+0,0033(\mathrm{P}-2)
\end{aligned}
$$

onde: MO é o teor de matéria orgânica $\left(\mathrm{g} \mathrm{kg}^{-1}\right) ; \mathrm{M}, \mathrm{a}$ soma dos teores de silte $\left(\mathrm{g} \mathrm{kg}^{-1}\right)$ e areia muito fina ( $\left.\mathrm{g} \mathrm{kg}^{-1}\right)$ multiplicados por 1.000 menos o teor de argila ( $\left.\mathrm{g} \mathrm{kg}^{-1}\right)$, sendo a análise granulométrica feita com uso de $\mathrm{NaOH} 1 \mathrm{~mol} \mathrm{~L}^{-1}$ como dispersante; S e P são os códigos referentes à estrutura e à permeabilidade (sem unidade).

\section{2) Lima et al. (1990)}

Adaptação do método anterior para latossolos brasileiros:

$$
\begin{aligned}
\mathrm{K}= & 1,451 \times 10-10(120-\mathrm{MO}) \mathrm{Ma1}, 14+ \\
& +0,0043(\mathrm{~S}-2)+0,0033(\mathrm{P}-2)
\end{aligned}
$$

onde: Ma tem o mesmo significado que $M$, porém a dispersão foi feita somente com água.

\section{3) Denardin (1990)}

$$
\begin{aligned}
& \text { Método para solos do Brasil: } \\
& \begin{aligned}
\mathrm{K} & =0,006084 \mathrm{P}+8,34286 \times 10^{-4} \mathrm{MO}- \\
& -1,1616 \times 10^{-4} \mathrm{Al}-3,776 \times 10^{-5} \mathrm{PART}
\end{aligned}
\end{aligned}
$$

onde: $\mathrm{Al}$ é o teor de $\mathrm{Al}_{2} \mathrm{O}_{3}$ da fração TFSA extraído pelo ataque sulfúrico $\left(\mathrm{g} \mathrm{kg}^{-1}\right)$ e PART, percentagem de partículas de diâmetro compreendi do entre 0,5 e $2 \mathrm{~mm}$ ( $\left.\mathrm{g} \mathrm{kg}^{-1}\right)$, usando-se $\mathrm{NaOH} 1 \mathrm{~mol} \mathrm{L-1.}$

4) Denardin (1990)

Método para solos do Brasil e dos EUA:

$$
\begin{aligned}
K & =7,48 \times 10-8 \mathrm{M}+0,00448059 \mathrm{P}- \\
& -0,0631175 \mathrm{DMP}+1,039657 \times 10-6 \mathrm{PROD}
\end{aligned}
$$

onde: DMP é o diâmetro médio ponderado da fração menor que $2 \mathrm{~mm}(\mathrm{~mm})$, PROD é o produto do teor de matéria orgânica $\left(\mathrm{g} \mathrm{kg}^{-1}\right)$ pela quantidade de partículas de diâmetro entre 0,1 e $2 \mathrm{~mm}\left(\mathrm{~g} \mathrm{~kg}^{-1}\right)$. E m todos os casos, a análise granulométrica foi feita usando-se $\mathrm{NaOH} 1 \mathrm{~mol} \mathrm{~L}^{-1}$.

\section{5) Rol off \& Denardin (1994)}

Método para solos do Estado do Paraná:

$\mathrm{K}=0,0049 \mathrm{P}+3,31 \times 10^{-5} \mathrm{Mm}^{0,5}$

onde: $\mathrm{Mm}$ é o teor de silte $\left(\mathrm{g} \mathrm{kg}^{-1}\right)$ multiplicado pela soma de silte e areia fina $\left(\mathrm{g} \mathrm{kg}^{-1}\right)$, sendo a análise granulométrica feita usando-se $\mathrm{NaOH} 1 \mathrm{~mol} \mathrm{L-1}$.

\section{6) Roloff \& Denardin (1994)}

Método para solos do Estado do Paraná:

$\mathrm{K}=1,038 \times 10-4 \mathrm{Mm} 0,5-4,54 \times 10-5 \mathrm{Al}$

\section{7) Rol off \& Denardin (1994)}

Método para solos com horizonte $B$ textural do Estado do Paraná:

$$
\begin{aligned}
\mathrm{K} & =9,17 \times 10^{-5} \mathrm{Mm}^{0,5}-5,26 \times 10^{-5} \mathrm{Fe}+ \\
& +1,76 \times 10^{-5} \mathrm{AF}
\end{aligned}
$$

onde: Fe é o teor de $\mathrm{Fe}_{2} \mathrm{O}_{3}$ da fraçãoTFSA extraído pelo ataque sulfúrico $\left(\mathrm{g} \mathrm{kg}^{-1}\right)$, e AF, o de areia fina $\left(\mathrm{g} \mathrm{kg}^{-1}\right)$, usando-se $\mathrm{NaOH} 1 \mathrm{~mol} \mathrm{L-1.}$

8) Römkens et al. (1977)

Método para subsolos argilosos dos EUA:

$\mathrm{K}=2,371 \times 10^{-7} \mathrm{M}-0,008$

9) Römkens et al. (1977)

Método para subsolos argilosos dos EUA:

$\mathrm{K}=5 \times 10^{-4}+3,0291 \times 10^{-7} \mathrm{M}-0,00142 \mathrm{Fe}_{d}+\mathrm{Al}_{\mathrm{d}}$

onde: $\mathrm{Fe}_{\mathrm{d}}+\mathrm{Al}_{\mathrm{d}}$ é a soma dos teores de $\mathrm{Fe}_{2} \mathrm{O}_{3}$ e $\mathrm{Al}_{2} \mathrm{O}_{3}$ extraídos pelo DCB $\left(\mathrm{g} \mathrm{kg}^{-1}\right)$.

10) Römkens et al. (1977)

Método para subsolos argil osos dos EUA:

$\mathrm{K}=0,1027-1,2 \times 10^{-4} \mathrm{ARG}$ 
onde: ARG é o teor de argila dispersa com $\mathrm{NaOH} 1 \mathrm{~mol} \mathrm{~L}^{-1}\left(\mathrm{~g} \mathrm{~kg}^{-1}\right)$.

11) Römkens et al. (1977)

Método para subsolos argilosos dos EUA:

$$
\begin{aligned}
\mathrm{K} & =0,0423+2,634 \times 10-7 \mathrm{M}- \\
& -0,0019 \mathrm{Fe}_{d}+\mathrm{Al}_{d}-0,011 \mathrm{Si}_{d}
\end{aligned}
$$

onde: $\mathrm{Si}_{d}$ é teor de $\mathrm{SiO}_{2}$ extraído pelo DCB $\left(\mathrm{g} \mathrm{kg}^{-1}\right)$.

12) El-Swaify \& Dangler (1977)

Método para solos do Havaí (EUA) quando secos:

$$
\begin{aligned}
\mathrm{K}= & =0,0017+1,449 \times 10^{-4} \mathrm{MQ}+ \\
& +2,371 \times 10^{-7} \mathrm{MH}-2,268 \times 10^{-4} \mathrm{SUS}- \\
& -0,041 \mathrm{pH}_{\mathrm{KCl}}+0,0361 \mathrm{pH}_{\text {água }}
\end{aligned}
$$

onde: $\mathrm{MQ}$ é o índice de instabilidade $\left(\mathrm{g} \mathrm{kg}^{-1}\right), \mathrm{MH}^{-} \mathrm{a}$ quantidade de areia maior que $0,1 \mathrm{~mm}\left(\mathrm{~g} \mathrm{~kg}^{-1}\right)$ multiplicada pela soma dos teores de silte $\left(\mathrm{g} \mathrm{kg}^{-1}\right)$ e areia muito fina ( $\mathrm{g} \mathrm{kg}-1$ ), usando-se $\mathrm{NaOH} 1 \mathrm{~mol} \mathrm{~L}^{-1}$; SUS, a soma dos teores de siltee argila, dispersos em água $\left(\mathrm{g} \mathrm{kg}^{-1}\right), \mathrm{pH}_{\mathrm{KCl}}, \mathrm{O} \mathrm{pH}$ do solo em solução $\mathrm{KCl} 1 \mathrm{~mol} \mathrm{L-1,} \mathrm{e} \mathrm{pHágua,} \mathrm{o} \mathrm{pH} \mathrm{do} \mathrm{solo} \mathrm{em} \mathrm{água.}$

\section{3) El-Swaify \& Dangler (1977)}

Método para solos do Havaí (EUA):

$$
\begin{aligned}
\mathrm{K} & =0,0052+4,1 \times 10^{-5} \mathrm{MQ}+5,66 \times 10^{-7 \mathrm{MH}+} \\
& +2,44 \times 10^{-4} \mathrm{~V}-3,4 \times 10^{-5} \mathrm{SI}-1,08 \times 10^{-4} \mathrm{AA}
\end{aligned}
$$

onde: $\mathrm{V}$ é a saturação por bases a pH 7 (\%), SI, o teor de silte $\left(\mathrm{g} \mathrm{kg}^{-1}\right)$, e AA, a soma dos teores das areias de diâmetro acima de $0,1 \mathrm{~mm}\left(\mathrm{~g} \mathrm{~kg}^{-1}\right)$. SI e AA foram obtidos usando-se $\mathrm{NaOH} 1 \mathrm{~mol} \mathrm{L-1}$.

Para a comparação dos métodos (direto x indiretos), efetuaram-se correlações de Pearson entre os valores de $\mathrm{K}$ medidos no campo (K obs.) e os avaliados pelos diferentes métodos indiretos (K est.) (Denardin, 1990). Essas correlações foram testadas quanto à sua significância pelo testet ao nível de 5\%.

\section{RESULTADOS E DISCUSSÃO}

Tentou-se seguir fiel mente os métodos originais, 0 que nem sempre foi possível. Os modelos originais muitas vezes não fornecem informações que possibilitariam sua reprodução analítica, ou distanciam-se demasiado dos procedimentos comumente usados nos laboratórios nacionais, o que dificulta sua adoção como procedimento de rotina. Em virtude disso, foram necessárias al gumas alterações nos procedimentos analíticos origi nais, visando tornáI os facilmente reproduzíveis. Os quadros 2 e 3 contêm os resultados analíticos dos parâmetros dos solos

\begin{tabular}{|c|c|c|c|c|c|c|c|c|c|c|c|}
\hline \multirow{2}{*}{ Solo } & \multirow{2}{*}{ MO } & \multicolumn{7}{|c|}{ Análise granulométrica ( $\left.\mathrm{NaOH} 1 \mathrm{~mol} \mathrm{~L}^{-1}\right)$} & \multirow{2}{*}{$M^{(6)}$} & \multirow{2}{*}{$S^{(7)}$} & \multirow{2}{*}{$P^{(8)}$} \\
\hline & & $A M G^{(1)}$ & $A G^{(2)}$ & $A M^{(3)}$ & $A F^{(4)}$ & $A M F^{(5)}$ & Silte & Argila & & & \\
\hline $\mathrm{N} \stackrel{0}{0}$ & \multicolumn{8}{|c|}{$-\mathrm{g} \mathrm{kg}^{-1}$} & $\mathrm{~g}^{2} \mathrm{~kg}^{-2}$ & & \\
\hline 1 & 9 & 43 & 134 & 192 & 328 & 132 & 60 & 111 & 170.688 & 4 & 2 \\
\hline 2 & 7 & 40 & 106 & 208 & 388 & 70 & 46 & 142 & 995.280 & 3 & 2 \\
\hline 3 & 22 & 4 & 45 & 134 & 199 & 97 & 303 & 218 & 312.800 & 4 & 4 \\
\hline 4 & 26 & 127 & 157 & 147 & 206 & 69 & 150 & 144 & 187.464 & 4 & 3 \\
\hline 5 & 24 & 20 & 132 & 138 & 138 & 53 & 141 & 378 & 120.668 & 4 & 3 \\
\hline 6 & 24 & 57 & 189 & 188 & 194 & 50 & 160 & 162 & 175.980 & 3 & 4 \\
\hline 7 & 12 & 18 & 50 & 116 & 265 & 217 & 144 & 190 & 292.410 & 2 & 5 \\
\hline 8 & 22 & 65 & 140 & 119 & 209 & 126 & 196 & 145 & 275.310 & 4 & 5 \\
\hline 9 & 7 & 16 & 97 & 180 & 316 & 160 & 120 & 111 & 248.920 & 4 & 5 \\
\hline 10 & 16 & 66 & 143 & 149 & 233 & 96 & 153 & 160 & 209.160 & 4 & 3 \\
\hline 11 & 16 & 57 & 137 & 135 & 199 & 87 & 194 & 191 & 227.329 & 4 & 3 \\
\hline 12 & 16 & 72 & 113 & 140 & 217 & 110 & 142 & 206 & 200.088 & 4 & 2 \\
\hline 13 & 19 & 53 & 120 & 128 & 183 & 79 & 129 & 308 & 143.936 & 4 & 1 \\
\hline 14 & 29 & 76 & 213 & 139 & 149 & 51 & 123 & 249 & 130.674 & 4 & 5 \\
\hline 15 & 12 & 23 & 45 & 60 & 278 & 259 & 202 & 133 & 399.687 & 4 & 3 \\
\hline 16 & 3 & 46 & 171 & 179 & 192 & 69 & 117 & 226 & 143.964 & 3 & 3 \\
\hline 17 & 48 & 14 & 47 & 69 & 89 & 39 & 367 & 375 & 253.750 & 4 & 2 \\
\hline 18 & 36 & 22 & 21 & 19 & 33 & 16 & 365 & 524 & 181.356 & 3 & 2 \\
\hline 19 & 16 & 5 & 87 & 230 & 279 & 81 & 106 & 212 & 147.356 & 4 & 4 \\
\hline 20 & 10 & 0 & 6 & 147 & 531 & 132 & 75 & 109 & 184.437 & 1 & 2 \\
\hline 21 & 22 & 52 & 155 & 123 & 147 & 55 & 150 & 318 & 139.810 & 4 & 3 \\
\hline 22 & 21 & 43 & 171 & 169 & 178 & 61 & 110 & 268 & 125.172 & 3 & 3 \\
\hline
\end{tabular}
empregados nos métodos indiretos de avaliação da erodibilidade.

Uma vez que as equações de estimativa da erodi bilidade não expressam relações causais, édifícil

Quadro 2. Teor de matéria orgânica (MO), análise granulométrica com dispersante químico, parâmetro M e códigos S (estrutura) e P (permeabilidade) dos solos estudados

${ }^{(1)} \mathrm{AMG}=$ areia muito grossa. ${ }^{(2)} \mathrm{AG}=$ areia grossa. ${ }^{(3)} \mathrm{AM}=$ areia média. ${ }^{(4)} \mathrm{AF}=$ areia fina. ${ }^{(5)} \mathrm{AMF}=$ areia muito fina. ${ }^{(6)} \mathrm{M}=(\mathrm{AMF}+\mathrm{Silte})\left(1.000\right.$ - Argila). ${ }^{(7)} 1=$ muito pequena granular; 2 = pequena granular; $3=$ média a grande granular; $4=$ blocos, laminar ou maciça. ${ }^{(8)} 1$ = rápida; 2 =moderada a rápida; 3 =moderada; 4 =lenta a moderada; 5 =lenta. 
precisar os motivos quelevaram aos resultados obtidos. $\mathrm{Na}$ análise das figuras 2 a 4, fica claro que, à exceção dos métodos de Römkens et al. (1977) e El-Swaify \& Dangler (1977), os model os forneceram valores aproximadamentedentroda faixa em quenatural mente ocorrem para esse grupamento de solos [0,004 a $0,045 \mathrm{th}(\mathrm{MJ} \mathrm{mm})^{-1}$. Nas figuras 2 a 4, encontram-se os coeficientes de correl ação entre os val ores do fator $K$ observados e os estimados por método.

A maioria dos trabal hos que ressal ta a inadequação do modelo de Wischmeier et al. (1971) o faz para latossol os (Henklain \& Freire, 1983; Lima, 1991; Silva et al., 1994). Atribui-se a inadequação desse modelo aos baixos teores de silte dos solos mais intemperizados (Denardin, 1990). Assim, havia a possibilidade de ser esse modelo adequado para solos não tão intemperizados, tais como os com horizonte $\mathrm{Bt}$, o que foi corroborado por Silva et al. (1986) e Campos Filho et al. (1992). Entretanto, tal possibilidade não severificou nestetrabal ho (Figura 2a) nem nos de Denardin (1990) e Silva (1994). E mbora, em condições equi paráveis, os solos com Bt tenham textura menos argilosa que os latossol os, mormente no horizonte superficial, seu teor em silte não é alto (Quadro 2), o que fez com que o parâmetro M médio fosse igual a $198.668 \mathrm{~g}^{2} \mathrm{~kg}^{-2}$, bem abaixo, portanto, do mínimo necessário para uma boa estimativa do fator $\mathrm{K}\left(300.000 \mathrm{~g}^{2} \mathrm{~kg}^{-2}\right)$ (Silva et al., 1994).

O método proposto por Lima et al. (1990) para estimativa da erodibilidadefundamenta-seno fatoque, em latossolos, as partículas de argila floculadas apresentam comportamento semelhante ao do silte e da areia muito fina, afetando o comportamento dos latossolos ante ao processo erosivo. Assim, ao fazer a dispersão do sol o usando-se água, obtêm-se, comumente, maiores teores de partículas com diâmetro correspondenteao siltee areia muito fina emenores de argila. O parâmetro Ma, como depende do teor de silte eareia muito fina, aumenta, portanto, várias vezes com a utilização de água como dispersante, podendo ficar acima de $300.000 \mathrm{~g}^{2} \mathrm{~kg}^{-2}$ (Lima et al., 1990; Silva et al., 1994). Contudo, neste trabalho, não foi observada a adequação desse modelo (Figura 2b), o que está de acordo com Silva et al. (1994). Como se pode visualizar na figura $2 \mathrm{~b}$, houveaumento nos val ores da erodibilidade, em comparação com o método anterior (Figura 2a), sem que esses valores tivessem correlação com o K observado. A inadequação desse método pode ser creditada ao baixo índice de floculação dos solos estudados, sendo que, mesmo dispersos emágua, poucos apresentaram Ma acima de $300.000 \mathrm{~g}^{2} \mathrm{~kg}^{-2}$ (Quadro3). Não obstante, os solos cujos fatores K estimados mais se aproximavam dos observados ( $\mathrm{F}$ igura $2 \mathrm{~b}$, polígono marcado) possuíam a relação $\mathrm{Ki}\left(\mathrm{SiO}_{2} / \mathrm{Al}_{2} \mathrm{O}_{3}\right)$ igual a $1,97 \pm 0,13$, enquanto, nos demais, essa relação valia $2,28+0,26$, havendo diferença estatística significativa (testet 1\%). Apesar dos resultados deSilva et al. (1994), o método de Lima et al. (1990) talvez seja adequado para solos mais intemperizados (baixo $\mathrm{Ki}$ ), independentemente de sua dassificação, tendo, assim, uma abrangência superior à proposta originalmente.

Quadro 3. Teores de $\mathrm{Fe}_{2} \mathrm{O}_{3}$ e $\mathrm{Al}_{2} \mathrm{O}_{3}$ extraídos pelo ataque sulfúrico (AS) e pelo ditionito-citrato-bicarbonato de sódio (DCB), teor de $\mathrm{SiO}_{2}$ extraído pelo DCB, índice de instabilidade (MQ), análise granulométrica utilizando água, parâmetro Ma, pH em KCI 1 mol L-1 e em água e saturação por bases a pH 7 (V) dos solos estudados

\begin{tabular}{|c|c|c|c|c|c|c|c|c|c|c|c|c|c|}
\hline \multirow{2}{*}{ Solo } & \multicolumn{2}{|c|}{$\mathrm{Fe}_{2} \mathrm{O}_{3}$} & \multirow{2}{*}{$\begin{array}{l}\mathrm{SiO}_{2} \\
\mathrm{DCB}\end{array}$} & \multicolumn{2}{|c|}{$\mathrm{Al}_{2} \mathrm{O}_{3}$} & \multirow{2}{*}{ MQ } & \multicolumn{3}{|c|}{ Análise gran. (água) } & \multirow{2}{*}{$\mathrm{Ma}^{(2)}$} & \multicolumn{2}{|c|}{ pH } & \multirow{2}{*}{$\mathbf{v}$} \\
\hline & AS & DCB & & AS & DCB & & $A M F^{(1)}$ & Silte & Argila & & $\mathrm{KCl}$ & $\mathrm{H}_{2} \mathrm{O}$ & \\
\hline No & & & & & $-\mathrm{g}$ & $\mathrm{kg}^{-1}$ & & & - & $\mathrm{g}^{2} \mathrm{~kg}^{-2}$ & & & $\%$ \\
\hline $\begin{array}{r}1 \\
2 \\
3 \\
4 \\
5 \\
6 \\
7 \\
8 \\
9 \\
10 \\
11 \\
12 \\
13 \\
14 \\
15 \\
16 \\
17 \\
18 \\
19 \\
20 \\
21 \\
22\end{array}$ & $\begin{array}{l}11 \\
10 \\
30 \\
20 \\
63 \\
40 \\
15 \\
30 \\
20 \\
39 \\
55 \\
28 \\
56 \\
18 \\
29 \\
28 \\
46 \\
66 \\
25 \\
23 \\
86 \\
52\end{array}$ & $\begin{array}{r}2 \\
0 \\
15 \\
6 \\
25 \\
14 \\
7 \\
4 \\
3 \\
10 \\
13 \\
10 \\
14 \\
4 \\
4 \\
10 \\
31 \\
34 \\
12 \\
4 \\
16 \\
16\end{array}$ & $\begin{array}{r}2 \\
3 \\
5 \\
3 \\
3 \\
3 \\
4 \\
3 \\
2 \\
4 \\
4 \\
4 \\
6 \\
5 \\
3 \\
5 \\
7 \\
10 \\
5 \\
2 \\
6 \\
6\end{array}$ & $\begin{array}{r}40 \\
51 \\
64 \\
59 \\
147 \\
75 \\
69 \\
59 \\
51 \\
72 \\
98 \\
119 \\
108 \\
82 \\
51 \\
82 \\
96 \\
161 \\
64 \\
43 \\
129 \\
110\end{array}$ & $\begin{array}{r}4 \\
2 \\
6 \\
6 \\
15 \\
3 \\
15 \\
5 \\
4 \\
4 \\
4 \\
2 \\
19 \\
9 \\
8 \\
5 \\
12 \\
12 \\
3 \\
3 \\
13 \\
4\end{array}$ & $\begin{array}{r}516 \\
412 \\
408 \\
64 \\
25 \\
147 \\
307 \\
224 \\
333 \\
229 \\
209 \\
344 \\
155 \\
132 \\
552 \\
163 \\
39 \\
75 \\
139 \\
65 \\
232 \\
72\end{array}$ & $\begin{array}{r}120 \\
75 \\
108 \\
80 \\
29 \\
58 \\
197 \\
158 \\
175 \\
95 \\
94 \\
116 \\
95 \\
54 \\
292 \\
75 \\
53 \\
22 \\
95 \\
132 \\
57 \\
64\end{array}$ & $\begin{array}{l}103 \\
110 \\
451 \\
181 \\
382 \\
182 \\
233 \\
246 \\
177 \\
169 \\
208 \\
205 \\
215 \\
194 \\
174 \\
196 \\
408 \\
486 \\
181 \\
87 \\
244 \\
192\end{array}$ & $\begin{array}{r}70 \\
74 \\
68 \\
36 \\
331 \\
150 \\
109 \\
61 \\
51 \\
101 \\
151 \\
138 \\
190 \\
137 \\
90 \\
130 \\
238 \\
396 \\
64 \\
58 \\
168 \\
150\end{array}$ & $\begin{array}{l}207.390 \\
171.310 \\
520.988 \\
251.604 \\
274.959 \\
204.000 \\
383.130 \\
379.356 \\
334.048 \\
237.336 \\
256.398 \\
276.702 \\
251.100 \\
214.024 \\
424.060 \\
235.770 \\
351.282 \\
306.832 \\
258.336 \\
206.298 \\
250.432 \\
217.600\end{array}$ & $\begin{array}{l}5,3 \\
4,3 \\
4,2 \\
3,8 \\
4,4 \\
7,1 \\
4,2 \\
4,7 \\
4,5 \\
5,3 \\
5,7 \\
5,9 \\
5,1 \\
4,1 \\
4,9 \\
5,0 \\
4,0 \\
4,6 \\
4,0 \\
4,5 \\
4,6 \\
4,7\end{array}$ & $\begin{array}{l}6,4 \\
5,6 \\
5,4 \\
5,6 \\
5,4 \\
7,7 \\
5,1 \\
5,6 \\
5,8 \\
5,8 \\
6,1 \\
6,5 \\
5,6 \\
4,8 \\
5,3 \\
5,4 \\
4,7 \\
5,8 \\
4,6 \\
4,9 \\
5,3 \\
5,4\end{array}$ & $\begin{array}{l}75 \\
56 \\
57 \\
62 \\
42 \\
89 \\
31 \\
77 \\
68 \\
83 \\
79 \\
82 \\
70 \\
24 \\
67 \\
56 \\
38 \\
64 \\
13 \\
42 \\
52 \\
53\end{array}$ \\
\hline
\end{tabular}

${ }^{(1)} \mathrm{AMF}=$ areia muito fina. ${ }^{(2)} \mathrm{Ma}=(\mathrm{AMF}+$ Silte) $(1.000$ - argila). 

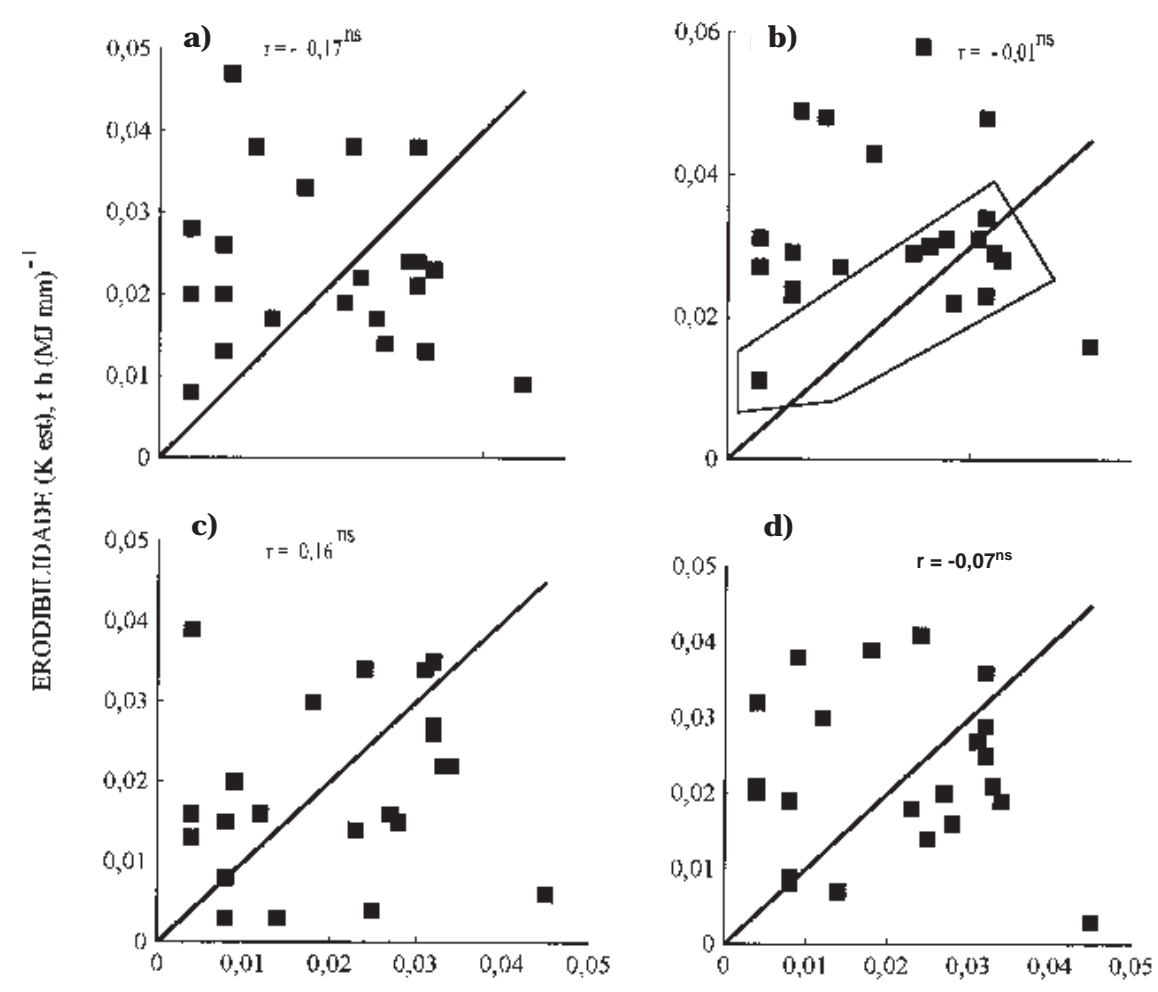

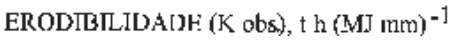

Figura 2. Relação entre o K estimado (K est.) pelos métodos 1 (a), 2 (b), 3 (c) e 4 (d) e o K observado (K obs.). O traço contínuo representa a linha 1:1 (ns = não significativo).

Os métodos de Denardin (1990), para solos do Brasil e para sol os do Brasil e dos EUA, também não foram adequados para a estimativa da erodibilidade dos solos estudados (Figuras 2c, d). Embora fosse esperado mel hor desempenho del es, Silva et al. (1994) também chegaram ao mesmo resultado. 0 método 4 (Figura 2d) apresentou maior dispersão dos dados, o que é compreensível, pois se baseia nos atributos de 77 solos, sendo, menos da metade, solos brasileiros (46 são oriundos dos EUA), o que o torna inadequado ao Brasil. O método usado para a análise granulométrica por Denardin (1990) preconiza o uso de agitação lenta por 16 horas, enquanto o utilizado nestetrabal ho e no de Silva et al. (1994) emprega agitação rápida por 20 minutos. Denardin (1990) também se afastou do procedimento convencional ao fazer a determinação do C orgânico em amostras previamente moídas em almofariz e passadas em peneira de malha de $0,117 \mathrm{~mm}$. E mbora esses fatos possam ter contribuído para a diferença encontrada nos valores de erodibilidade estimados de K, não é essa a principal explicação para a falta de correlação. Possivel mente, ela esteja mais associada à ind usão, neste estudo, de sol os que, não tendosido pesquisados por Denardin (1990), apresentaram K estimados muito distantes dos observados. Os sol os de número 2 e 17 tipificam isso, com $\mathrm{K}$ est., pelo método 3 , i quais a 0,006 e0,039 $\mathrm{h}(\mathrm{MJ} \mathrm{mm})^{-1}$, eK obs. iguais a 0,045 e0,004 th (MJ mm)-1 respectivamente. Silva et al. (1994) apontam o pequeno número de parâmetros envolvidos nesses métodos como uma de suas limitações.
Também os de Roloff \& Denardin (1994) não forneceram resultados satisfatórios (Figuras 3a, b, c); visando desenvolver métodos que permitissem estimar a erodibilidade de solos do Paraná, retrabal haram os dados de Denardin (1990), de modo a excluir os sol os que tivessem atri butos pouco comuns aos ocorrentes no Paraná. Dessa forma, foram geradas quatro equações de previsão da erodibilidade, entre elas uma específica para solos com Bt. Entretanto, mesmo essa equação apresentou grande dispersão de pontos, estando sujeita aos mesmos comentários feitos para as equações de Denardin (1990). É de notar que mesmo o solo número 17, de Morretes (PR), tem seu fator $\mathrm{K}$ observado igual a 0,004 th (MJ mm)-1), bem distante daquele estimado pelas equações [K est. pelo método 7 igual a $\left.0,037 \mathrm{t} \mathrm{h}(\mathrm{MJ} \mathrm{mm})^{-1}\right]$.

Os model os de Römkens et al. (1977) apresentaram resultados muito insatisfatórios, produzindo até mesmo valores de $\mathrm{K}$ negativos (Figuras $4 a, b, c, d$ ). Denardin (1990) também chegou a idênticos resultados. Um dos motivos que levou a isso podeter sido o método usado por el es para a anál ise granul ométrica, que implicou na destruição prévia de vários agentes agregantes $\left(\mathrm{CaCO}_{3}\right.$, matéria orgânica eóxidos de Fe) e a uti lização de car bonato de sódio como dispersante (Denardin, 1990), sendo grandea diferença entreesse método e o usado neste trabalho. Os modelos de Römkens et al. (1977), excetuando-se o método 10 (Figura 4c), são fundamentados nos al tos coeficientes de correlação entre a variável $\mathrm{M}$ e a erodibilidade. Contudo, essa elevada correlação não se verificou 

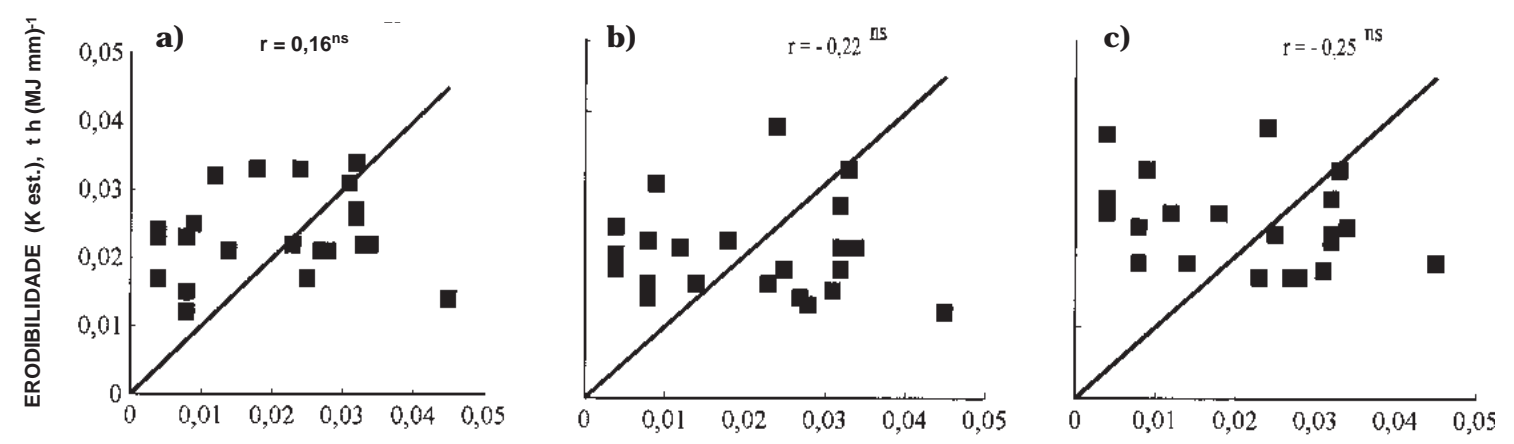

ERODIBILIDADE (K obs.), th (MJ mm)-1

Figura 3. Relação entre o K estimado (K est.) pelos métodos 5 (a), 6 (b), 7 (c) e o K observado (K obs.). 0 traço contínuo representa a linha 1:1 (ns = não significativo).
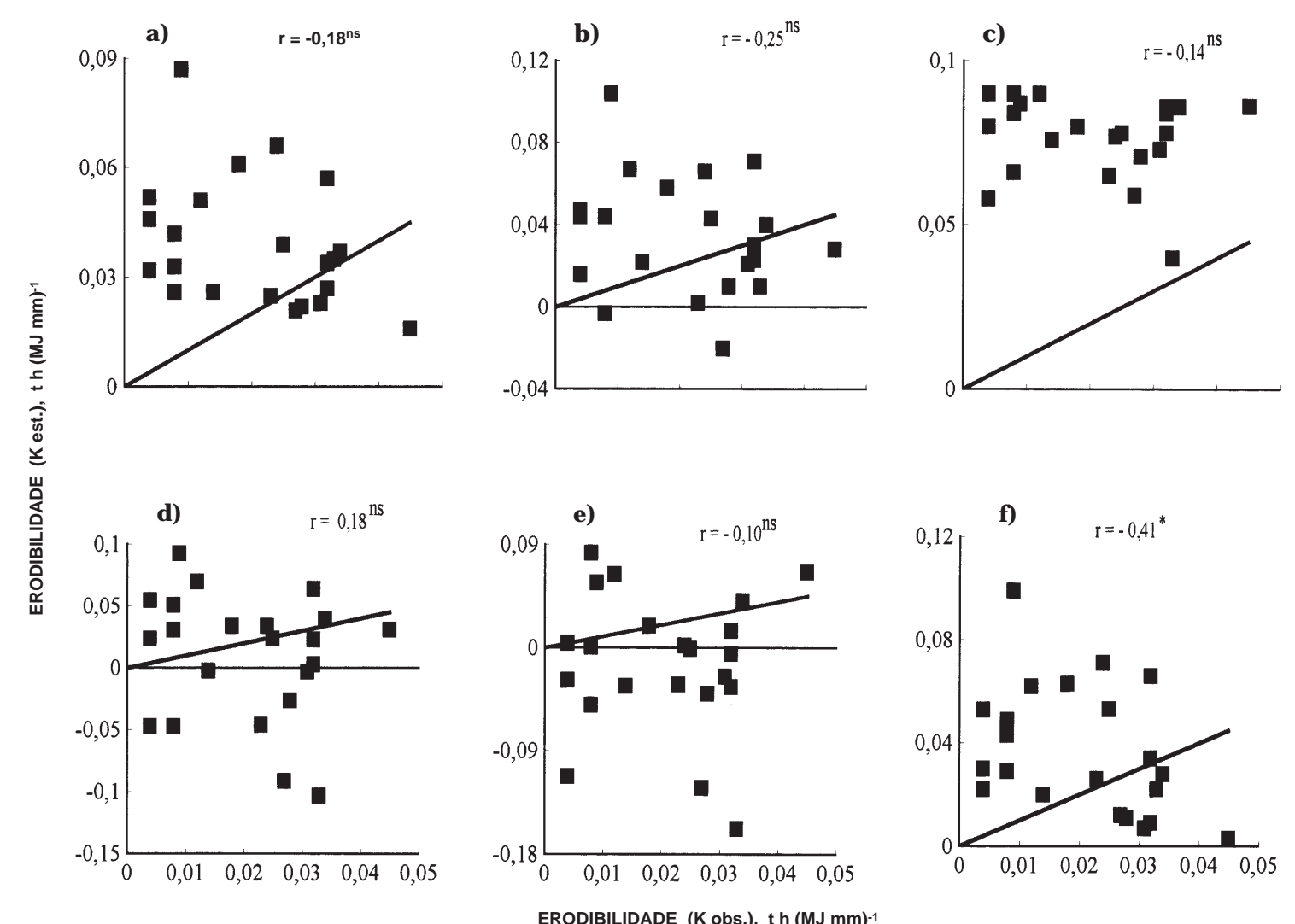

Figura 4. Relação entre o K estimado (K est.) pelos métodos 8 (a), 9 (b), 10 (c), 11 (d), 12 (e) e 13 (f) e o K observado (K obs.). 0 traço contínuo representa a linha 1:1 (* = significativo ao nível de 5\%; ns = não significativo).

nestetrabalho ( $r=-0,14$, nãosignificativo). A inclusão dos teores de $\mathrm{Fe}_{2} \mathrm{O}_{3}, \mathrm{Al}_{2} \mathrm{O}_{3}$ e $\mathrm{SiO}_{2}$, extraídos pelo DCB nessas equações, baseia-se no efeito agregante que essas frações teriam no solo, porém o DCB extrai também formas não tão efetivas na agregação das partículas, sendo esse um dos motivos de sua inadequação a sol os brasilei ros (Denardin, 1990). Provavelmente, entretanto, a razão principal do pouco sucesso desses model os seja ofato de ter em sido gerados para subsolos (o horizonte A foi, propositadamente, removido) com altos teores de silte e argila, os quais diferem, substancial mente, da maioria dos horizontes superficiais dos sol os aqui estudados (Quadros 2 e 3).

À semel hança dos demais, os métodos deEI-Swaify \& Dangler (1977) forneceram valores estimados sem relação com a erodi bi lidade observada (Figuras $4 \mathrm{e}, \mathrm{f}$ ). Não houve diferença entre as três formas de representar oíndice deinstabilidade, por isso somente foram mostrados os valores de $\mathrm{K}$ referentes ao índice MQ determinado sem pré-umedecimento (Quadro 3). 
O método 12 (Figura 4e) chegou a fornecer valores negativos para o fator $\mathrm{K}$. Isso é compreensível, pois essa equação foi desenvolvida com valores de K determinados por meio de chuvas simuladas estando o solo inicialmente seco (El-Swaify \& Dangler, 1977). O método sugerido por EI-Swaify \& Dangler (1977), para quantificação da variável SUS, foi considerado de reprodução difícil, sendo, por isso, alterado. Obviamente, isso implicou no aumento da imprecisão do método, ainda que, por si só, seja insuficiente para explicar a grande divergência de resultados. O método 13 (Figura 4f) não fornece resultados negativos, mas superestima em demasia a erodibilidade dos sol os. As diferenças metodológicas na análise granulométrica ena determinação da saturação por bases contribuíram para a ineficiência do modelo, mas, possivelmente, a inadequação do model o se ache mais ligada aos solos usados por El-Swaify \& Dangler (1977). Dos dozesolos por el es estudados (todos de regi ões tropicais), apenas dois (ultissol os) podem ser considerados semel hantes aos destetrabal ho; os demais (oxissolos, inceptissol os, vertissolos earidissolos) possuem atributos extremamente diversos e, por conseguinte, grande variedade de comportamento ante à erosão.

Como se pode verificar nas figuras 2 a 4 , praticamente todos os solos têm sua erodibilidade corretamente estimada por algum dos métodos. Contudo, não foi encontrado nenhum critério lógicocientífico que justificasse a exclusão de certos solos e a recomendação de um dado método para outros.

\section{CONCLUSÃO}

Nenhum dos métodos indiretos estudados se mostrou recomendável para a estimativa do fator $\mathrm{K}$ para todo o conjunto de solos com horizonte $B$ textural do Brasil, utilizados neste estudo. Assim, sugere-se que sejam desenvol vi dos métodos de avaliação do fator $\mathrm{K}$ especificamente para sol os brasileiros com horizonte B textural.

\section{AGRADECIMENTOS}

Os autores agradecem aos pesquisadores e professores D. Reinert (UFSM), E. Margolis (UFRPE), G.R. Curcio (EMBRAPA), I.B. Chaves e I.F. Silva (UFPB), J.R.C. Silva (UFC), L.H.C. Anjos (UFRRJ), M. Resende (UFV), N. Kämpf (UFRGS), R.C. Alvarenga (EMBRAPA) e S.C.F. Dechen (IAC), pelas amostras de sol o gentilmente enviadas.

\section{LITERATURA CITADA}

BRYAN, R.B.; GOVERS, J. \& POESEN, J. The concept of soil erodibility and some problems of assessment and application. Catena, Cremlingen, 16:393-412, 1989.

CAMARGO, M.N.; KLAMT, E. \& KAUFMANN, J.H. Classificação de solos usada em levantamentos pedológicos no Brasil. B. Inf. SBCS, Campinas, 12:11-33, 1987.
CAMARGO, O.A.; MONIZ, A.C.; J ORGE, J.A. \& VALADARES, J.M.A.S. Métodos de análise química, mineralógica e física de solos do Instituto Agronômico de Campinas. Campinas, IAC, 1986. 94p. (Boletim técnico, 106)

CAMPOS FILHO, O.R.; SILVA, I.F.; ANDRADE, A.P. \& LEPRUN, J.C. Erosividade da chuva e erodibilidade do solo no agreste de Pernambuco. Pesq. agropec. bras., Brasília, 27:1363-1370, 1992.

CARVALHO, M.P.; CATANEO, A. \& LOMBARDI NETO, F. Fator erosividade da chuva e enxurrada para chuvas individuais de Pindorama (SP). In: REUNIÃO BRASILEIRA DE MANEJ O E CONSERVAÇÃO DO SOLO E DA ÁGUA, 10., Florianópolis, 1994. Resumos. Florianópolis, SBCS, 1994. p.150-151.

CARVALHO, M.P.; LOMBARDI NETO, F.; VASQUES FILHO, J. $\&$ CATANEO, A. Índices de erosividade da chuva correlacionados com as perdas de solo de um podzólico vermelho-amarelo eutrófico textura argilosa/muito argilosa de Mococa (SP): primeira aproximação do fator erodibilidade do solo. R. bras. Ci. Solo, Campinas, 13:237-242, 1989.

DAL CONTE, F.M. Índice de erodibilidade de um solo podzólico vermelho-amarelo, determinado sob chuva simulada. Santa Maria, UFSM, 1982. 67p. (Dissertação de Mestrado)

DAY, P.R. Particle fractionation and particle - size analysis. In: BLACK, C.A., ed. Methods of soil analysis. Madison, American Society of Agronomy, 1965. v.1, p.545-566.

DENARDIN, J.E. Erodibilidade de solo estimada por meio de parâmetros físicos equímicos. Piracicaba, ESALQ, 1990. 81p. (Tese de Doutorado)

EL-SWAIFY, S.A. \& DANGLER, E.W. Erodibilities of selected tropical soils in relation to structural and hydrologic parameters. In: NATIONAL CONFERENCE ON SOIL EROSION, West Lafayette, 1976. Proceedings. Ankeny, SWCS, 1977. p.105-110.

EMBRAPA. Manual de métodos de análise de sol os. Rio de J aneiro, EMBRAPA-SNLCS, 1979. n.p.

HENKLAIN, J.C. \& FREIRE, O. Avaliação do método nomográfico para determinação da erodibilidade de latossolos do Estado do Paraná. R. bras. Ci. Solo, Campinas, 7:191-195, 1983.

KEMPER, W.D. \& ROSENAU, R.C. Aggregate stability and size distribution. In: KLUTE, A., ed. Methods of soil analysis. Madison, American Society of Agronomy, 1986. v.1, p.425442.

LAL, R. Erodibility and erosivity. In: LAL, R., ed. Soil erosion research methods. Ankeny, Soil Water Conservation Society, 1988. p.141-160.

LIMA,J .M.; CURI, N.; RESENDE, M. \& SANTANA, D.P. Dispersão do material de solo em água para avaliação indireta da erodibilidade em latossolos. R. bras. Ci. Solo, Campinas, 14:85-90, 1990.

LIMA, P.M.P. Í ndices de erodibilidade diretos e indiretos para dois latossolos do município de Lavras - Minas Gerais. Ci. Prát., Lavras, 15:186-193, 1991.

McKEAGUE, J.A. Manual on soil sampling and methods of analysis. Ottawa, CSSS, 1978. 212p.

MARQUES, J.J.G.S.M. Estimativas e comparações dos fatores erosividade das chuvas eerodibilidade de sol os com horizonte B textural no Brasil. Lavras, UFLA, 1996. 119p. (Dissertação de Mestrado)

MEHRA, O.P. \& J ACKSON, M.L. I ron oxide removal from soils and clays by a dithionite-citrate system buffered with sodium bicarbonate. Clays Clay Min., Clarkson, 3:317-327, 1960. 
RENARD, K.G.; FOSTER, G.R.; YODER, D.C. \& MCCOOL, D.K. RUSLE revised: status, questions, answers and the future. J. Soil Water Cons., Ankeny, 49:213-220, 1994.

RESCK, D.V.S.; FIGUEIREDO, M.S.; FERNANDES, B.; RESENDE, M. \& SI LVA, T.C.A. Erodibilidade de um podzólico vermel ho-amarelo câmbico distrófico fase terraço, localizado na Zona da Mata (MG), determinada com simulador de chuva. R. bras. Ci. Solo, Campinas, 5:7-14, 1981.

RODRIGUES do Ó, N.C. Erodibilidade das principais classes de solo do Estado da Paraíba determinada por chuva simulada e método nomográfico. Areia, UFPB, 1986. 29p. (Dissertação de Graduação)

ROLOFF, G. \& DENARDIN, J.E. Estimativa simplificada da erodibilidade do solo. In: REUNIÃO BRASILEIRA DE MANEJ O E CONSERVAÇÃO DO SOLO E DA ÁGUA, 10., Florianópolis, 1994. Resumos. Florianópolis, SBCS, 1994. p.150-151.

RÖMKENS, M.J.M. The soil erodibility factor: a perspective. In: HARLIN, J.M. \& BERARDI, G.M., eds., Agricultural soil loss: processes, policies and prospects. Boulder, Westview, 1987. p.125-149.

RÖMKENS, M.J.M.; ROTH, C.B. \& NELSON, D.W. Erodibility of selected clay subsoils in relation to physical and chemical properties. Soil Sci. Soc. Am. J., Madison, 41:954-960, 1977.

SILVA, I.F. \& ANDRADE, A.P. Relatório de pesquisa sobre conservação do sol o: 1977-1978. Areia, SUDENE/UF PB, 1994. v.1, n.p.
SILVA, I.F.; ANDRADE, A.P. \& CAMPOS FILHO, O.R. Erodibilidade de seis solos do semi-árido paraibano obtida com chuva simulada e método nomográfico. R. bras. Ci. Solo, Campinas, 10:283-287, 1986.

SILVA, J.R.C. Erodibilidade dos solos do Ceará: distribuição espacial e avaliação de métodos para sua determinação (1a aproximação). Fortaleza, Universidade Federal do Ceará, 1994. 60p. (Tese de Professor Titular)

SILVA, M.L.N.; CURI, N.; OLIVEIRA, M.S.; FERREIRA, M.M. \& LOMBARDI NETO, F. Comparação de métodos direto e indiretos para determinação da erodibilidade em latossolos sob cerrado. Pesq. agropec. bras., Brasília, 29:1751-1761, 1994.

VETTORI, L. Métodos de análise de solos. Rio de J aneiro, Ministério da Agricultura-E quipe de Pedologia e Fertilidade do Solo, 1969. 24p. (Boletim técnico, 7)

WEAVER, R.M.; SYERS, J.K. \& J ACKSON, M.L. Determination of silica in citrate-bicarbonate-dithionite extracts of soils. Soil Sci. Soc. Am. Proc., Madison, 32:497-501, 1968.

WISCHMEIER, W.H.; J OHNSON, C.B. \& CROSS, B.V. A soil erodibility nomograph for farmland and construction sites. J. Soil Water Cons., Ankeny, 26:189-193, 1971.

WISCHMEIER, W.H. \& SMITH, D.D. Predicting rainfall erosion Iosses: a guide to conservation planning. Washington, USDA, 1978. 58p. (Agriculture Handbook, 537) 